\title{
Use of a Seismic Derived Constraint: Different Steps and Joined Uncertainties in the Construction of a Realistic Geological Model
}

\author{
B. Doligez ${ }^{1}$, H. Beucher ${ }^{2}$, O. Lerat ${ }^{1}$ and O. Souza ${ }^{3}$ \\ 1 Institut français du pétrole, IFP, 1-4 avenue de Bois-Préau - 92852 Rueil-Malmaison Cedex - France \\ 2 CG Fontainebleau, 35, rue Saint-Honoré - 77305 Fontainebleau - France \\ 3 Petrobras, Brésil, Av. Republica do Chile, 65/1702 - 20031-912 - Rio de Janeiro - RJ Brazil \\ e-mail: brigitte.doligez@ifp.fr - helene.beucher@ensmp.fr - olivier.lera@@ifp.fr - olinto@petrobras.com.br
}

\begin{abstract}
Résumé - Intégration d'une contrainte dérivée de la sismique : revue des différentes étapes et quantification des incertitudes associées à la construction du modèle géologique - La construction d'un modèle géologique réaliste est l'un des premiers objectifs du processus de caractérisation de réservoir. Ce terme résume les différentes étapes menant à l'obtention d'un modèle 3D intégrant toute l'information a priori disponible, le modèle géologique conceptuel, les données géologiques, de sismique et de production, avant la simulation des écoulements. La définition du meilleur «modèle géologique réaliste » à obtenir doit être donnée en considérant l'objectif final de l'étude : il peut s'agir d'obtenir une réalisation qui respecte au mieux les paramètres géologiques et les contraintes dérivées de la sismique, ou de produire une réalisation qui reproduira au mieux les données de production.

L'intégration d'une information sismique est cruciale pour cette modélisation. Beaucoup de travaux récents ont porté sur des méthodes visant à introduire dans les modèles probabilistes une contrainte secondaire, caractérisée par une relation souvent indirecte avec les propriétés réservoir. À cause des échelles de résolution différentes entre sismique et géologie, et de la relation complexe qui existe entre les propriétés des roches et la réponse sismique, il peut être efficace d'extraire dans un premier temps une propriété géologique des données sismiques, puis de contraindre la simulation de faciès en utilisant cette propriété. L'extraction d'une contrainte géologique moyenne des données sismiques se fait à partir d'une calibration statistique sur les données de puits. Deux approches sont principalement utilisées, basées sur des méthodes de segmentation ou sur des techniques d'estimation. Le résultat en terme de variables corrélées avec la distribution de faciès se présente sous forme de contraintes $2 \mathrm{D}$ c'est-à-dire de cartes reliées à l'épaisseur totale de l'unité stratigraphique étudiée, ou à de petits volumes à l'intérieur de l'unité (contrainte 3D). L'Institut français du pétrole et le Centre de Géostatistique de l'École des Mines ont développé une méthodologie innovante qui permet de générer des grilles de proportions de faciès à partir de données de puits et de modèles sédimentologiques conceptuels (cartes et zonations) tout en étant contraintes par une information dérivée de la sismique.
\end{abstract}

L'objectif de ce papier est de présenter une analyse et une évaluation de l'impact réel de ces contraintes dérivées de la sismique sur le modèle géologique de réservoir en termes de quantification des incertitudes, de la distribution des hétérogénéités et des caractéristiques géologiques clés. Ces tests supposent que le modèle structural du réservoir est fixé et que le modèle géologique conceptuel est 
déterminé en termes d'interprétations et d'environnements. Ils ont pour but d'explorer les variations possibles des paramètres utilisés dans les scénarios servant à remplir l'espace en propriétés géologiques.

À l'aide d'un jeu de données réelles, différentes contraintes et différentes méthodes d'intégration de la sismique sont comparées. Leur impact est analysé dans le cadre de la méthode de simulation par les gaussiennes tronquées pour être ensuite comparé aux incertitudes existantes sur certaines données géologiques.

\begin{abstract}
Use of a Seismic Derived Constraint: Different Steps and Joined Uncertainties in the Construction of a Realistic Geological Model - Realistic geological modeling can be considered as the first objective in a reservoir characterization workflow. This term describes the process of building static 3-D reservoir models based on available a priori information, geological interpretations and quantitative geological, seismic, and production data. The definition of the best "realistic geological model" to be produced has to be discussed depending on the target objective: to produce a simulation which honors at best the geological parameters and the seismic derived constraints or to produce a simulation which will fit at best the production data.

The incorporation of seismic information is a crucial element in reservoir geological modeling. Many recent research works have focused on the introduction in probabilistic models of secondary data characterized by a relationship, often indirect, with the reservoir properties. Due to the different scales of resolution between seismic and geology and to the complex relationship between rock properties and seismic response, a logical process can be to firstly extract geological properties from seismic data and second to constrain the facies simulation using these properties. The extraction of soft geological information from seismic data relies on statistical calibration with well data. Mainly two approaches can be used, either based on supervised segmentation or on estimation techniques. The obtained information consists in variables correlated with the facies distribution. Depending on the available information the variables can be related to the total thickness of the studied stratigraphic unit (leading to $2 D$ constraints as maps) or to small volumes inside the unit (3D constraints). IFP-CG (Institut français du pétrole Centre de Géostatistique of the École des Mines) have developed an innovative methodology to generate facies proportions grids from well data, sedimentological conceptual models (maps and zonations), and constrained with seismic derived information.

The objective of this paper is to present an analysis and evaluation of the real impact of these seismic derived constraints on the reservoir geological model in terms of quantification of uncertainties, heterogeneities distribution, and key geological characteristics. In the geomodelisation workflow, this work takes place when the structural framework of the reservoir is determined and also when the geological conceptual model is defined in terms of interpretation, environment, and layering. Its purpose is to investigate possible variations in parameterization of the scenarios of filling the space with geological properties.

Using a real data case, different constraints and different methods of seismic integration are compared. Their impact of seismic in the framework of the truncated gaussian methodology and compared to the impact of the uncertainty on geological data.
\end{abstract}

\section{INTRODUCTION}

This paper has two main objectives: first, to apply on a real dataset a workflow and a methodology for geological reservoir modeling using a seismic derived constraint, and second, to perform a detailed analysis and an evaluation of the impact of parameters and constraints, with associated uncertainties on the geological model.

The geological heterogeneity is nowadays classically recognized as a major factor controlling the reservoir production (Dutton et al., 2003; Eaton, 2006). However it is impossible to exactly predict between wells the unique true distribution of reservoir properties. Geological uncertainty is an inherent characteristic of any geological model. Geostatistics can be used to quantify uncertainty in the geological model through the construction of multiple equally probable realizations of reservoir properties. The difference between geological realizations which are obtained using a set of parameters is a statistical measure of geological uncertainty for a given model (Deutsch et al., 2002).

The integration of seismic information in reservoir description can lead to a considerable improvement in the quality of 
the final distribution. Seismic data provide valuable information regarding the lateral variation of lithology not given by the sparse well control. Numerous stochastic modeling methods exist now to integrate data of different sources and nature: here seismic and lithology. However each step of the process in order to get the final set of selected geostatistical realizations of the reservoir involves interpretations: fitting of models, selection of methods and parameters (the choice of the simulation method for example). It depends strongly on the type and the distribution of the variable to be simulated and also on its relationship with seismic.

In this paper we use the truncated gaussian method in a non stationary framework (Doligez et al., 1999; Johann et al., 1996) to generate 3D images of the reservoir. In this method the seismic derived information is used in the estimation of local proportions of facies, which define the values of thresholds for truncation.

Among the multiple possible scenarios for reservoir characterization and uncertainties quantification, the present work takes place when the depositional environment is determined and when the structural geometry is estimated. The purpose of this paper is to illustrate on a real dataset the impact of some of the choices and interpretations made for filling a grid with geological properties on the resulting geological realizations and on their ranking. Comparison of geostatistical realizations which are obtained using varying parameters is not an easy nor straight process. Dynamic ranking accounts for the production mechanisms, but tends to undermine the geological uncertainty through its simplifying assumptions (McLennan and Deutsch, 2005). Static ranking measures are straightforward and important. They could be used to preselect geological realizations using geological criteria and knowledge in order to perform history matching adjustments on realistic images of the reservoir. Several criteria have to be considered, as global measurements (volumes, original oil in place or OOIP, net to gross ratio, net volumes), as average distribution of parameters (maps of proportions), and also as connectivity criteria.

\section{GEOLOGICAL MODELING WORKFLOW}

The first objective in a reservoir characterization workflow, meaning the process of building a 3D grid with geological properties, also called the static model, can be considered as the integration of data in order to obtain a realistic geological model.

The workflow for reservoir characterization and modeling is far to be standard (Fig. 1) and essentially depends on the regional geology, the field history (appraisal, development or production phases) and the quality and amount of conditioning data (Cosentino, 2001).

The model can be obtained through a first facies modeling constrained with hard data only (well data), or hard data plus a seismic information, and using deterministic or stochastic methods (Fig. 1-A). The choice of the facies modeling method (pixel or object based) essentially depends on the geological framework and on the issue which is addressed. The integration of seismic as auxiliary information for the facies modeling may contribute to better represent key heterogeneities and reduce reservoir description uncertainties.

The petrophysical properties distribution can then be computed according to the geological facies. It could also be obtained through a direct property modeling, without considering a previous facies distribution. However this distribution is generally guided by an analysis of the geological environment or the delineation of architectural elements.

The methods used for the petrophysical property modeling can be deterministic (estimation of a given property value for each environment), or stochastic (geostatistical simulations), and can use well data only or well data and a seismic constraint (Fig. 1-B).

The use of seismic has to be consistent all along the workflow, and depends on the modeling approaches. The seismic data may be interpreted as seismic facies probability cubes, or geological facies probability or proportions maps or volumes for facies modeling. They can also be used as pseudo property cubes or trends for petrophysical property modeling.

The main difficulties related to the integration of seismic constraints are the quality of the seismic itself and of the horizons picking, its resolution and its difference of scale with geological data. For these reasons 2D seismic maps of average properties are often preferred to 3D seismic cubes, also because they often present a better fit with well data.

This paper goes through one of the possible workflows, using the non stationary truncated gaussian stochastic approach for facies modeling and estimation methods constrained by the geology for property modeling. In this framework the simulation method requires the definition of a 3D grid of proportions which will be computed using seismic data.

\section{FIELD DATA}

The reservoir under study consists of Cenomanian / Turonian (96.5MY-92MY) turbidites interbedded with marls and shales (Gomes de Souza, 1997; Johann et al., 1996). The individual sand bodies are lenticular and elongated northwest-southeast. 56 wells are available, and have been interpreted in terms of four facies (very porous sandstones, sandstones, shales and silts) defined from well data combining sequence stratigraphy interpretation, core and log description (Fig. 2).

This study focuses on the Upper reservoir unit, which is around $100 \mathrm{~m}$ thick.

From the data provided by Petrobras several maps of different seismic attributes are also available. 


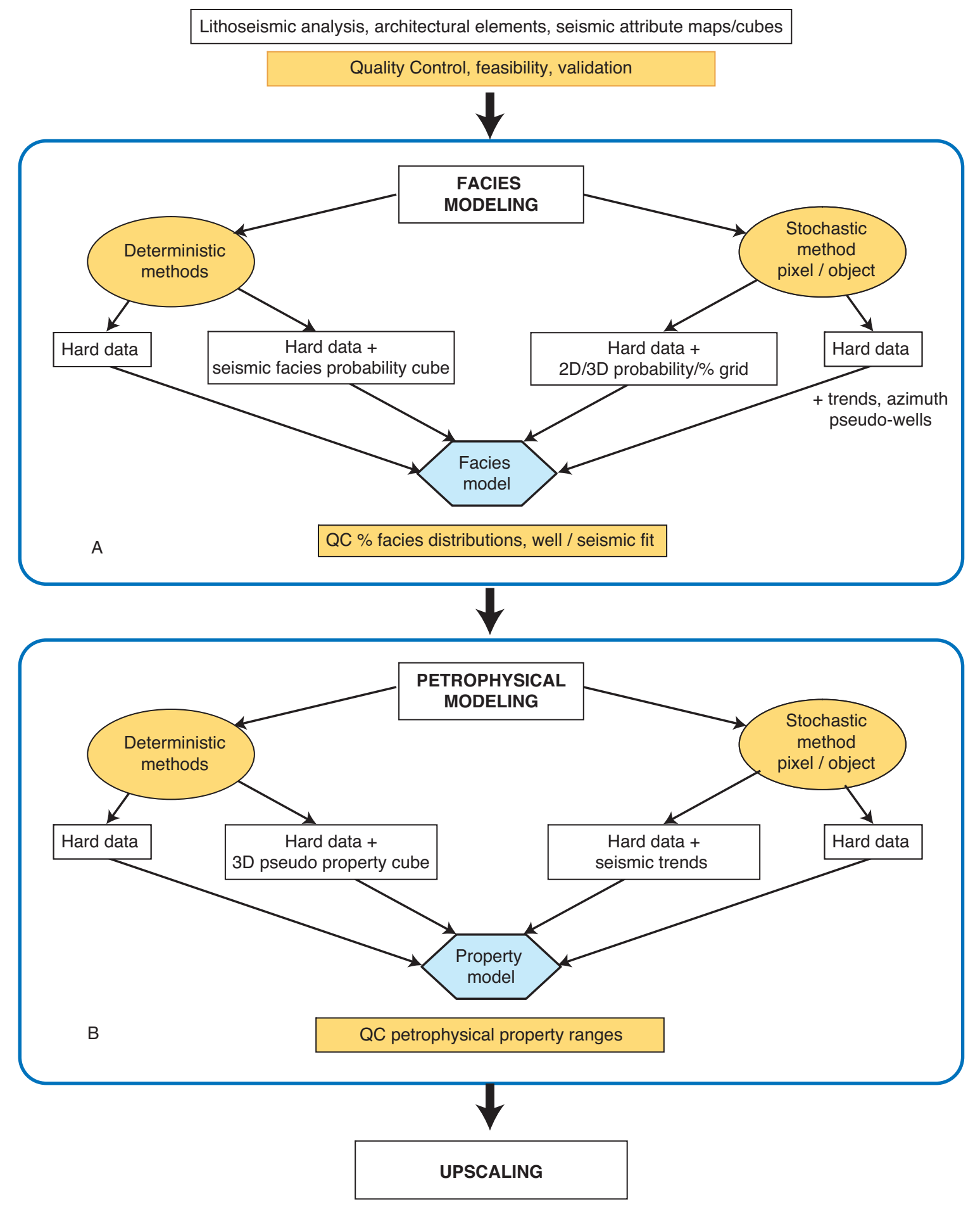

Figure 1

Different possible workflows for reservoir characterization.

The construction of a reservoir model can be performed directly in terms of 3D distribution of petrophysical properties in the reservoir for fluid flow simulation or through a first step of geological modeling, then petrophysical properties modeling before up-scaling for fluid flow simulations. The methods can be deterministic or stochastic and integrate seismic constraint if available. 


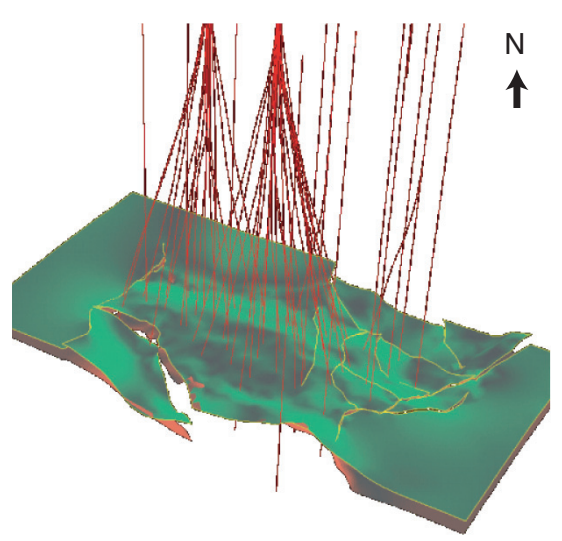

Data for structural model: well trajectories, horizons and faults

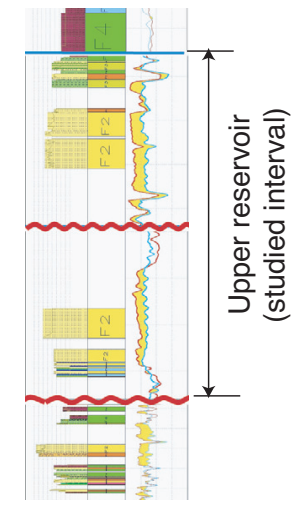

Net thickness

$5 \mathrm{~m}<<115 \mathrm{~m} ;$ Ø: $20-30 \%$

Well data: logs, markers, facies

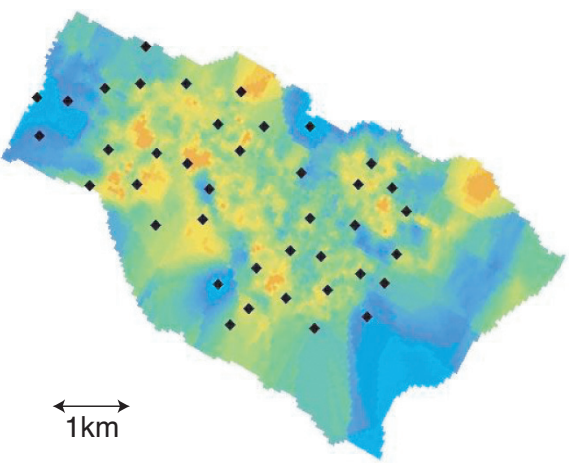

Map of seismic attribute: spatial distribution of a seismic parameter related to the reservoir properties and location of wells

Figure 2

Case study dataset:

56 wells (logs and cores) seismic data interpreted in terms of seismic attributes, horizons.

\section{STEP BY STEP METHODOLOGY}

The 3D reservoir model will be generated using the truncated Gaussian method in the non stationary framework, which needs a variogram model and a 3D matrix of proportions as input parameters. The integration of seismic and geological data consists in first assessing average or local facies proportions from some related seismic parameters, together with associated uncertainties. In a second step this information is integrated in the computation of the proportion matrix. This allows in particular to deal with cases where seismic parameters are strongly not linearly correlated to the reservoir properties. It also offers a large panel of possible techniques to account for spatial correlations and management of uncertainties.

\subsection{Computing a Map of Proportions of Sands from Seismic}

The estimation of the spatial distribution of sand proportions, constrained by a seismic attribute linked to these proportions, can be performed either by co-kriging or using the seismic information as external drift, depending on their relationship. The co-kriging method is based on the knowledge of the bivariate model, simple and cross-variograms (related to sand proportions and seismic attribute).

Figure 3 displays the experimental simple variograms computed from well data for sand proportions, for one of the available seismic attribute and the cross variogram between the two variables, again at well locations. These experimental curves are fitted with two different models (spherical or cubic) and different ranges. Each model represents a possible interpretation of the spatial continuity and correlation between the two variables, which can be used for further estimation of maps of sand proportions. This step is linked to interpretations and choices depending on the number and quality of data.

Figure 4 displays examples of extreme results in terms of maps of average proportions of sands in the Upper unit of the reservoir, which are obtained using the first seismic attribute and collocated cokriging estimation method (a) or the second seismic attribute as an external drift for the estimation (b). On one hand the use of a cokriging system requires fitted models of simple and cross variograms between the two variables which is an interpretative process as illustrated on Figure 3. On the other hand the external drift method seems easier to use but is also an interpretation assuming that the secondary variable provides low-frequency information about the primary one and is perfectly known. The geological interpretation of seismic attributes must of course be the guide and the final judge to keep the most significant map. However several possible interpretations always exist and have to be considered in the evaluation of global uncertainties.

\subsection{Truncated Gaussian Methodology}

The principles behind the truncated gaussian simulation method have been published in several reference papers 

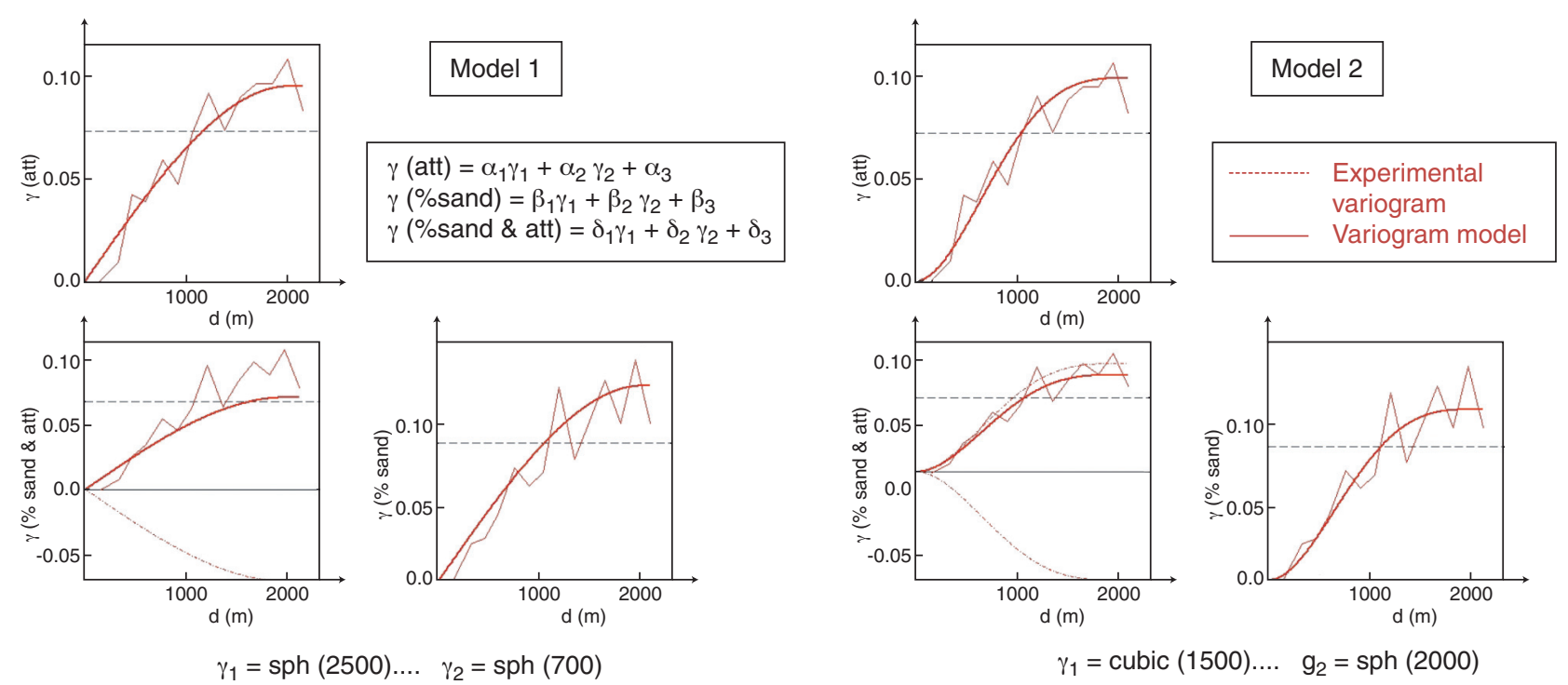

Figure 3

Correlation functions between seismic attribute and proportions of facies.

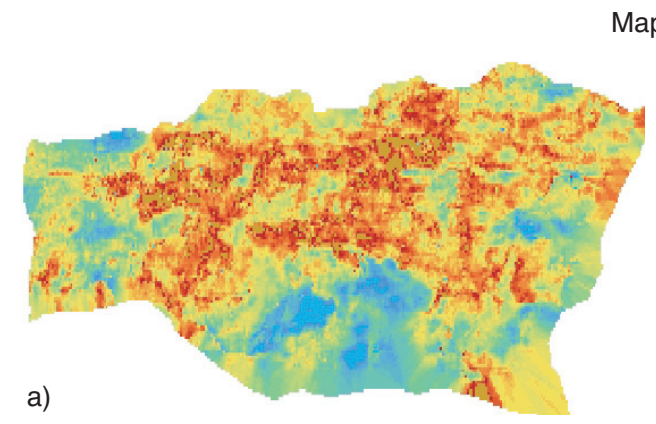

Using

- variogram model1

- cokriging with map of seismic attribute 1

Map of average \% sands

Figure 4

Different possible maps of proportions of sand.

(Journel and Isaaks, 1984; Matheron et al., 1987; Rudkiewicz et al., 1990; Galli and Beucher, 1997). They may be summarized in three main steps:

A Computation of the 3D proportions from well and seismic data,

B Simulation of a gaussian field of values using the variogram model fitted on experimental indicator variograms,

C Truncation of the gaussian field with thresholds computed from the $3 \mathrm{D}$ proportions to obtain the facies field.

A The data available to compute the 3D distribution of proportions are first the $1 \mathrm{D}$ well data, which provide a very

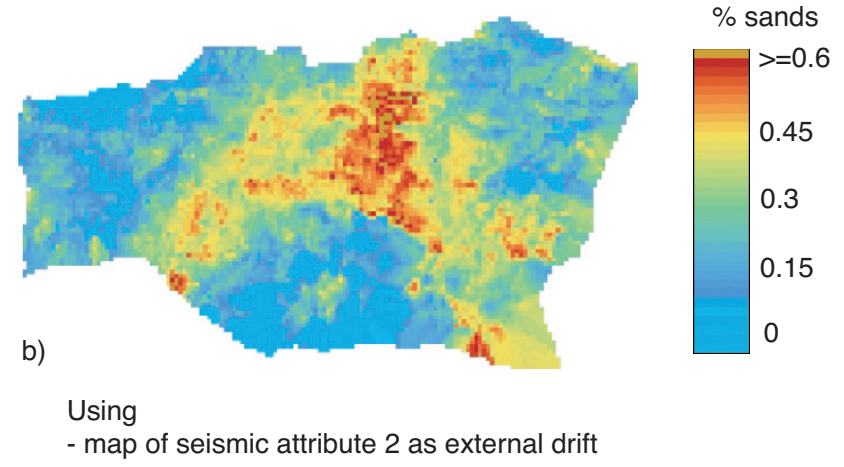

- map of seismic attribute 2 as external drift detailed vertical distribution of the facies, and second a 2D map of average proportions of sands computed from seismic data, which provides a continuous spatial information. The idea is to integrate these different scales and type of data in the computation of the 3D grid of proportions.

The 3D grid of proportions represents the 3D average distribution of geological facies in the studied area. It is now recognized as an important tool allowing the integration of fine-scale sedimentological heterogeneity and improving the precision and accuracy of static reservoir models and volumetric calculations (Labourdette et al., 2005). The objective in the computation of this distribution of propor- 


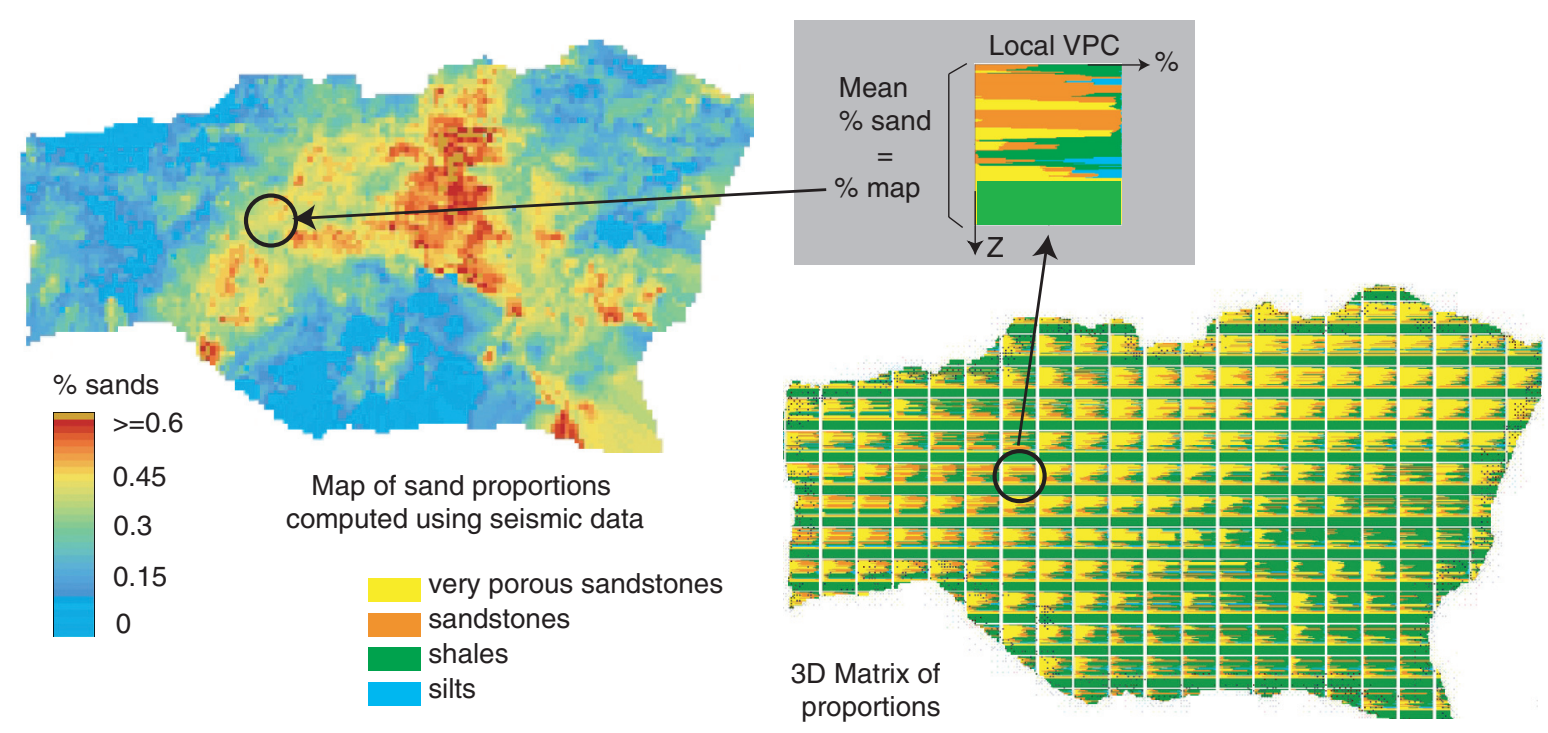

Figure 5

3D matrix of proportions computed using a map of trend of proportions.

tions is to account for the maximum amount of data, qualitative and quantitative, from geological interpretations and seismic derived maps (Doligez et al., 2002).

In practice, a grid is defined as a partition of the studied area. On each cell of this grid, the proportions $\operatorname{prop}_{f, z}(x)$ corresponding to the proportion of facies $f$ at location $x$ in the plane $z$ are estimated using ordinary kriging of local proportions, computed from wells or groups of wells $\left(\operatorname{prop}_{f, z}\left(x_{i}\right)\right)$ in the plane $z$ of the considered cell.

prop $_{f, z}(x)=\sum_{i=1}^{N} \lambda_{i ; f, z}$ prop $_{f, z}\left(x_{i}\right) ;$ N_VPC corresponds to the number of initial vertical proportion curves.

The variance of estimation var $\left[\operatorname{prop}_{f, z}\left(x_{0}\right)-\operatorname{prop}_{f, z}\left(x_{0}\right)\right]$ is minimum with two constraints: - the universality constraint $\sum_{i=1}^{N} \sum_{i, f, z}=1$ (for each plane
$z$ and for each facies $f$ );

- a constraint related to the seismic derived information which must be consistent with the vertical average of sand proportions: $S_{f}(x)=\sum_{z=1}^{N z}$ prop $_{f, z}(x)$ where $S_{f}(x)$ corresponds to the value of sand proportions read on the seismic map at location $x$ (Fig. 5), and also named aggregation constraint (Moulière et al., 1997).

Seismic data generally provide smooth variations of proportions as they represent mean proportions on a $3 \mathrm{D}$ bloc at the seismic resolution. Well data provide mean proportions related to the same vertical interval but with an horizontal "point" support at well location. This may explain why at well locations the mean proportion of a facies is often not equal to the value given by seismic data. In practice it is important to define the size of the proportion grid as a function of seismic resolution and this requires special attention when the size of the cells of the proportion grid is the same as the one corresponding to well data.

In our case which is non stationary, the proportions vary over the whole domain according to the $3 \mathrm{D}$ grid of proportions which have been computed previously integrating seismic constraint.

The 3D grid of proportions displayed on Figure 5 is a 3D mosaic grid covering the studied area. Each 2D cell of the grid is filled with a local vertical proportion curve which represents the local geological vertical sequence of facies. It is now recognized as an important tool allowing the integration of fine-scale sedimentological heterogeneity and improving the precision and accuracy of static reservoir models and volumetric calculations. Generating such a facies probability cube or 3D grid of facies proportions is a critical step of the facies modeling workflow.

B The simulation of the underlying gaussian field needs a variogram model $\rho(h)$, which is obtained from the experimental variograms (horizontal and vertical) of the facies indicator functions computed from well data (Fig. 6[1]).

C The spatial distribution of facies is the result of the truncation of the gaussian field simulated using $\rho(h)$, with thresholds $t_{i}$ computed from the previous 3D proportions. These thresholds define a partition of the random values into different classes associated to the geological facies (Fig. 6 [2] and [3]). 
(1) Generation of a 3D gaussian field of random values
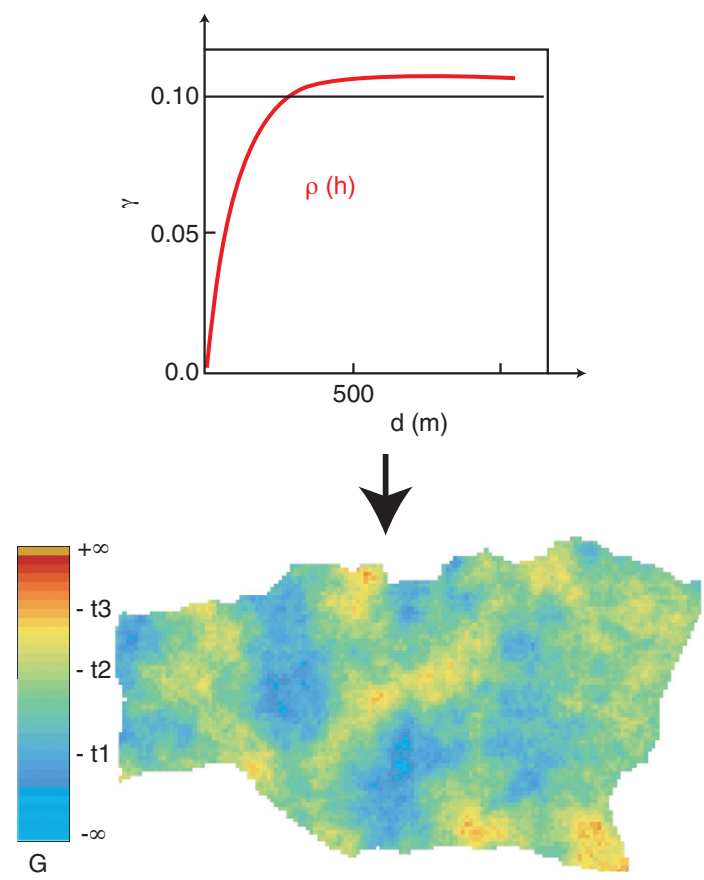

(2) Computation of thresholds using proportions

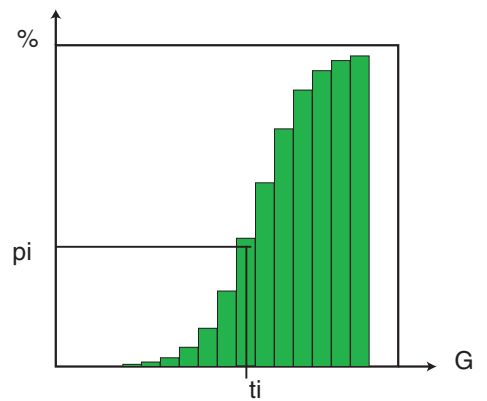

(3) Partition of the field of random values
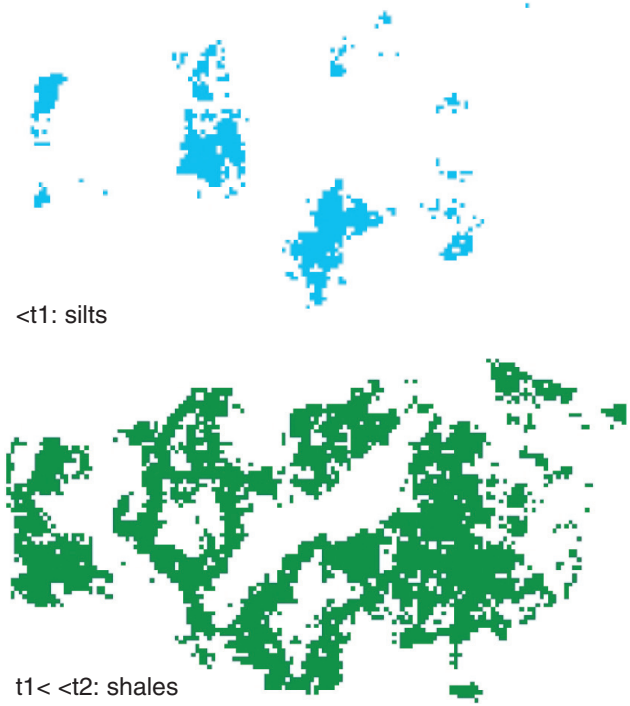

$\mathrm{t} 1<<\mathrm{t} 2$ : shales

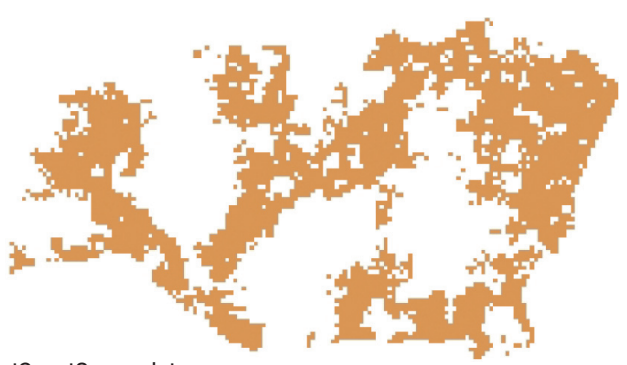

$\mathrm{t} 2<<\mathrm{t} 3$ : sandstones

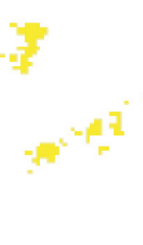

$>\mathrm{t} 3$ : very porous sandstones
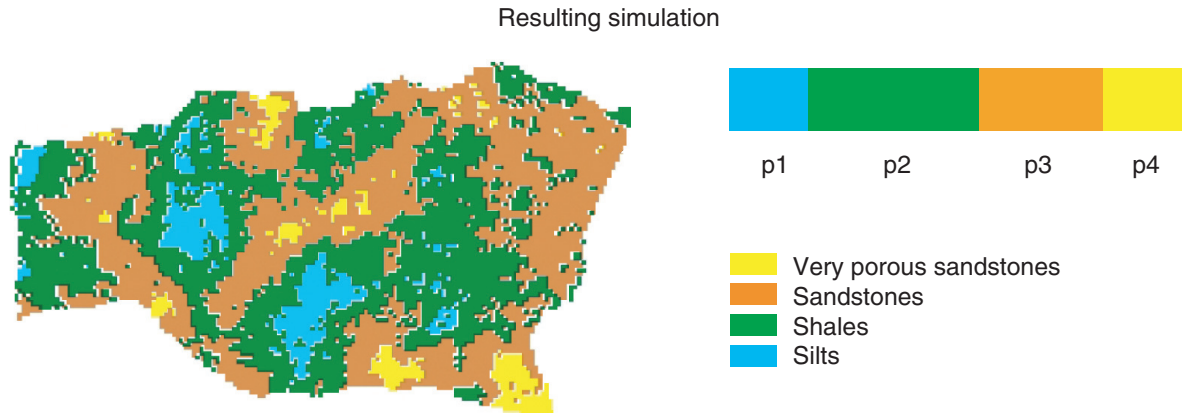

Very porous sandstones

Sandstones

Shales

Silts

Figure 6

Illustration of the truncated gaussian methodology.

This figure illustrates the different steps of the methodology from the generation of a 3D gaussian field of random values to the result in terms of geological facies. On this example, the facies proportions are supposed to be constant over the field. In that case, the proportion of silts corresponds to a first level of truncation $\mathrm{t} 1$, which defines the areas where silts are distributed. A second truncation $\mathrm{t} 2$ associated to the proportion of shale defines the range of values between $\mathrm{t} 1$ and $\mathrm{t} 2$ corresponding to shale distribution, and so on. 

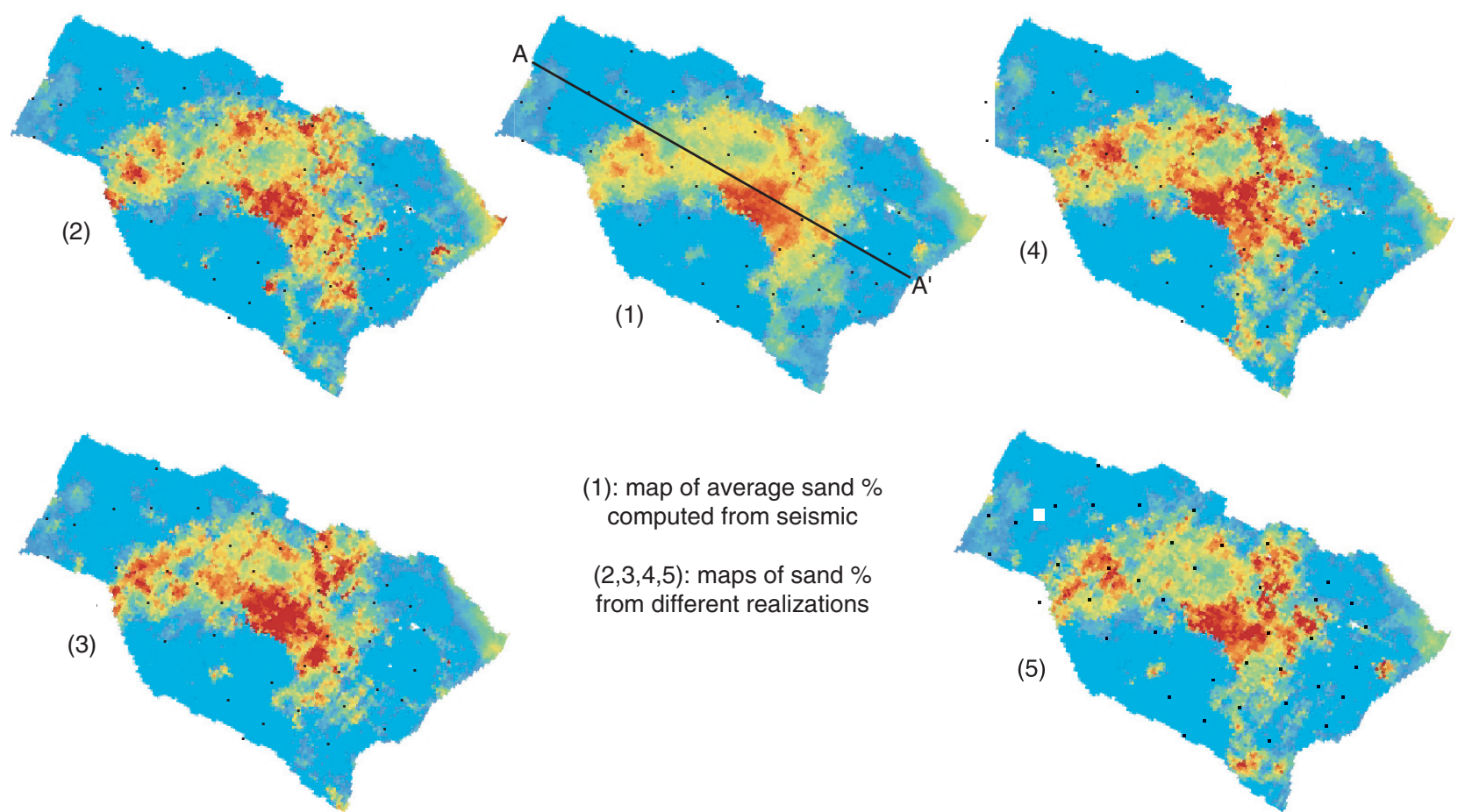

(1): map of average sand \%
computed from seismic

$(2,3,4,5)$ : maps of sand \% from different realizations

\section{Figure 7}

Maps of cumulated proportions of reservoir facies between top and bottom compared to the map of trend of proportions computed previously.

As a geostatistical simulation process is involved, numerous possible realizations may be generated honoring the hard data which are the well data, and honoring statistically the seismic constraint through the grid of proportions.

\section{SENSITIVITY ANALYSIS}

\subsection{In Terms of Reservoir Proportions}

The analysis and impact of geology on reservoir flow simulation is important. For example thin shale barriers will have a significant impact when reservoir production depends on vertical flow. The variability of the shale barriers is thus important to be captured in the geologic modeling.

In order to have a visual comparison of the results and to evaluate their variability, maps of average proportions of sands computed from different realizations using the previously discussed parameters have been computed, with a focus on the profiles of proportions displayed along the line AA' of the Figure 7.

The individual profiles of sand proportions computed on 10 realizations, the average profile from these 10 realizations, and the sand proportion profile computed from the seismic map are displayed on Figure 8. The individual variability could also be quantified on this result around the average plus or minus two times the standard deviation of the distribution.

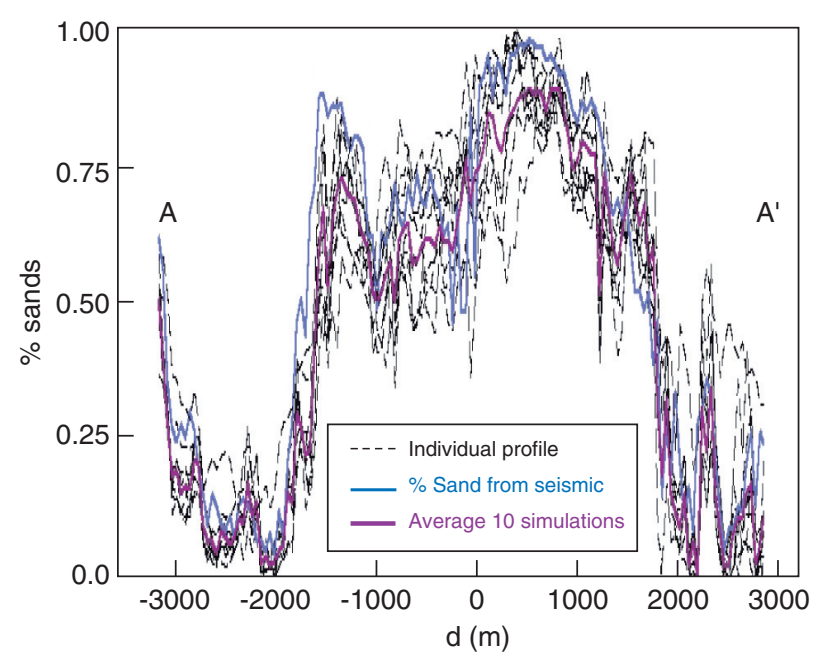

Figure 8

Profiles of cumulated proportions of reservoir facies along A-A'. 


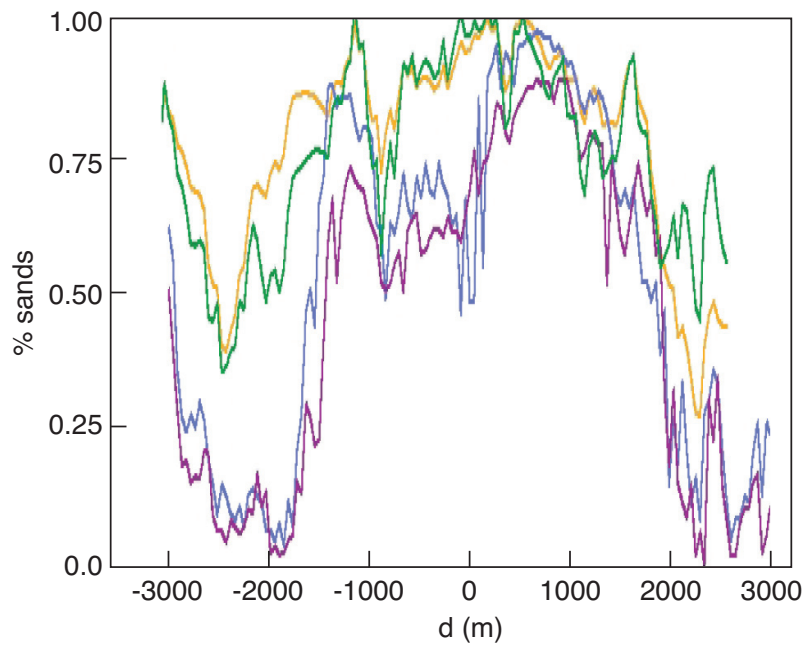

Three possible profiles of sand \% computed from seismic: - trend1: kriging with external drift (seismic attribute1)

- trend2: kriging with external drift (seismic attribute2) - trend3: collocated cokriging with seismic attribute2 and average 10 simulations constrained by trend 1

Figure 9

Variability of trends of sand proportions computed from seismic. 1st connected component gross volume (shale) from 50 realizations

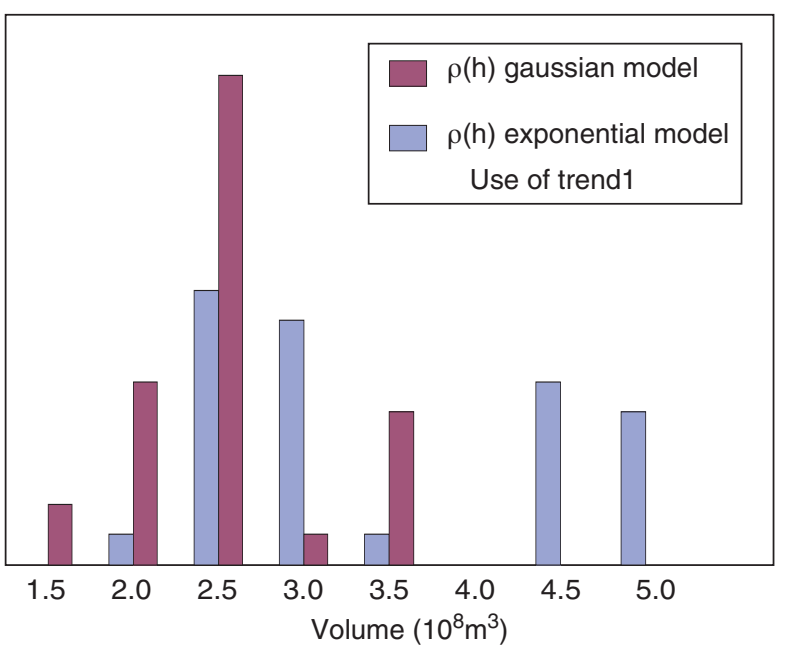

Figure 10

Variability of simulations due to the variogram model quantified in terms of volume of the first connected component of shale.
This analysis shows the relative individual high variability of the realizations, in particular in locations which are far from conditioning wells. This corresponds to the geological uncertainty, translated in terms of statistics.

This also shows the weight of the 3D grid of proportions which corresponds to the average behavior of the results. The weight of the seismic integration in such a process is crucial, as the seismic data directly constrain the 3D distribution of proportions of facies.

This proportion distribution corresponds to the average behavior of the model, and all the choices which have been discussed in the first part of this paper also become crucial. Figure 9 displays three possible profiles of sand proportions computed on from different seismic attributes: these three trends of sand proportions will generate different families of realizations. This illustrates the uncertainty on interpretation, which should be accounted for in the analysis of the results.

\subsection{In Terms of Connectivity}

Conventional global connectivity calculations indicate the proportion of net reservoir that is connected within the drainage volume. The impact of a second parameter which is the variogram model fitted or chosen to generate the $3 \mathrm{D}$ gaussian values is illustrated on Figure 10. These histograms correspond to the distribution of the volumes of the connected barrier facies (shale) computed from 50 realizations in each case, and using different variogram models.

The exponential model results in more noisy images where packs of cells can be connected or not, depending on small scale variability of the facies distribution. This explains the distribution in two modes of the corresponding histogram (in blue).

\subsection{In Terms of Net to Gross Ratio}

In the reservoir modeling workflow the construction of the geological model is followed with the estimation, or simulation of physical properties related to the facies, using or not a seismic constraint.

From the data of our field case, a distribution of porosities has been computed for each facies. Using these distributions, different methods have been used to compute a porosity value in each cell of the grid according to the facies.

Figure 11 displays different histograms of the resulting global N/G computed on 50 realizations for each test. The first distribution (in blue) corresponds to a facies model generated with an exponential model of variogram, and a random sampling of the porosity values according to the distribution corresponding to each facies. The second distribution 
N/G histograms from 50 realizations

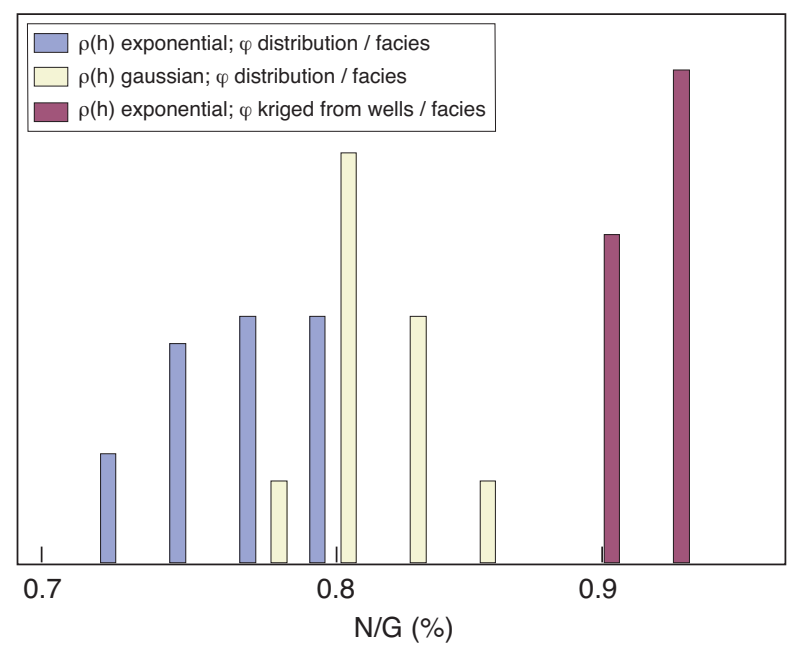

Figure 11

Histograms of N/G distributions computed on 50 realizations for different variograms and different methods of petrophysical properties computation.

(in white) corresponds to a similar process, but using a gaussian model of variogram for the facies generation. Results obtained with this approach are in the same order of magnitude than the first one in terms of $\mathrm{N} / \mathrm{G}$ distribution. The third distribution (in purple) corresponds to a kriging of the porosities for each facies.

The kriging process allows to account for the trend in the spatial distribution of the values which can explain the differences between this family of distributions and the others.

This test points out the importance of the transition from facies to petrophysical properties distribution, adding around $10 \%$ to the uncertainty on the estimation of the net to gross ratio and thus volumetric estimations.

\section{CONCLUSIONS}

The purpose of this work was to investigate possible choices of methods and parameters for filling the space between wells with geological properties. These tests have been realized assuming that the structural and geological frameworks are determined. They allow to quantify some uncertainties linked to geostatistical scenarios which have to be added to geological and seismic uncertainties.

Some key points can summarize this overlook on the reservoir modeling workflow integrating a seismic constraint:

- The reservoir modeling process is far to be a standard process. Randomly selecting geological realizations does not accurately represent uncertainty. Each step of the process and each parameter has an impact on the final result. The number of possible combinations is large but all the choices must result in a model consistent with the geological characteristics of the field.

- We have presented one possible methodology for incorporating seismic information in stochastic simulations of facies applied on a real field study. A strong point in this approach is the ability to simulate the facies at a fine scale while accounting for larger scale seismic derived information. The approach is flexible as the constraints can be taken into account using different methods, but this demonstration also shows some crucial points which have to be checked carefully. More generally for any of these methods allowing to merge seismic and well information, the quality of the well to seismic tie is important, but also the seismic parameterization.

- The petrophysical properties modeling is another key point which controls the final result. It is as important as the facies modeling step in its variety of possible methods and in its impact on the final results.

\section{REFERENCES}

Cosentino L. (2001) Integrated reservoir studies. IFP Publications, Ed. Technip.

Deutsch C.V., Dembicki E., Yeung K. (2002) Geostatistical determination of production uncertainty: Application to Fire bag project. Center for Computational Geostatistics (CCG), University of Alberta, Edmonton, Alberta, Canada.

Doligez B., Beucher H., Geffroy F., Eschard R. (1999) Integrated reservoir characterization: improvement in heterogeneous stochastic modeling by integration of additional external constraints. In Schatzinger R. and Jordan J. (Eds.), Reservoir Characterization Recent Advances, AAPG Memoir 71,333-342.

Doligez B., Fournier F., Jolivet G., Gançarski S., Beucher H. (2002) Seismic facies map integration in geostatistical geological model: a field case. EAGE - 64th conference and exhibition of the European Association of Geoscientists \& Engineers, Florence, 27-30 May 2002, Extended abstracts 2, 215-218.

Dutton S.P., Flers W.A., Barton M.D. (2003) Reservoir characterization of a Permian deep-water sandstone, East Ford Field, Delaware Basin, Texas. AAPG Bull. 87, 609-627.

Eaton (2006) On the importance of geological heterogeneity for flow simulation. Sediment. Geol., 184, 187-201.

Galli A., Beucher H. (1997) Stochastic models for reservoir characterization: a user-friendly review. SPE38999.

Gomes de Souza O. Jr (1997) Stratigraphie séquentielle et modélisation probabiliste des réservoirs d'un cône sous-marin profond (Champ de Namorado, Brésil). Intégration des données géologiques et géophysiques. $\mathrm{PhD}$ Thesis, Université Paris 6.

Labourdette R., Imbert P., Insalaco E., Hegre J.A. (2005) Reservoirscale $3 D$ sedimentary modeling: Approaches and impact of integrating sedimentology into the reservoir characterization workflow. The Future of Geological Modeling in Hydrocarbon Development Conference. The Geological Society of London, Burlington House, Piccadilly, London. 
Johann P., Fournier F., Souza O., Eschard R., Doligez B., Beucher H. (1996) 3D stochastic reservoir modeling constrained by well and seismic data on a turbidite field. SPE36501.

Journel A.G., Isaaks E.H. (1984) Conditional indicator simulation: application to a Saskatchewan uranium deposit. J. Math. Geol., 16, 685-718.

Matheron G., Beucher H., de Fouquet C., Galli A., Guerillot D., Ravenne C. (1987) Conditional simulation of the geometry of fluvio deltaic reservoirs. SPE 62nd Annual Conference, Dallas, Texas, 591-599.

McLennan J.A., Deutsch C.V (2005) Ranking Geostatistical realizations by measures of connectivity. SPE/PS-CIM/CHOA 98168.
Moulière D., Beucher H., Hu L.Y., Fournier F., Terdich P., Melchiori F., Griffi G. (1997) Integration of seismic derived information for reservoir stochastic modeling using truncated Gaussian approach. In Baafi E.Y. and Schofield N.A. (Eds.), Geostatistics Wollongong '96, Vol. 1, Kluwer Academic Pub., Dordrecht.

Rudkiewicz J.L., Guérillot D., Galli A. (1990) An integrated software for stochastic modeling of reservoir lithology and property with an example from the Yorkshire Middle Jurassic. In Buller et al. (Eds), North Sea Oil and Gas reservoirs, II; Graham \& Trotman Ltd., 399-406.

Final manuscript received in June 2006 or distributed for profit or commercial advantage and that copies bear this notice and the full citation on the first page. Copyrights for components of this work owned by others than IFP must be honored. Abstracting with credit is permitted. To copy otherwise, to republish, to post on servers, or to redistribute to lists, requires prior specific permission and/or a fee: Request permission from Documentation, Institut français du pétrole, fax. +33147527078 , or revueogst@ifp.fr. 